\title{
Application of Exponential Smoothing to Machining Precision of Nickel-based Superalloy Waspaloy
}

\author{
Shao-Hsien $\mathrm{Chen}^{1 *}$ and Yu-Lun $\mathrm{Ho}^{2}$ \\ ${ }^{1}$ The Graduate Institute of Precision Manufacturing, National Chin-Yi University of Technology, \\ No. 57, Sec. 2, Zhongshan Rd., Taiping Dist., Taichung 41170, Taiwan (R.O.C.) \\ ${ }^{2}$ Department of Mechanical Engineering, National Chin-Yi University of Technology, \\ No. 57, Sec. 2, Zhongshan Rd., Taiping Dist., Taichung 41170, Taiwan (R.O.C.)
}

(Received February 20, 2019; accepted February 26, 2020)

Keywords: exponential smoothing, Waspaloy, nickel-based, superalloy, tool wear

Nickel-based materials are widely used in engines, housings, and compressor rotors. They are also used in other industries, such as energy, petrochemicals, and tool and die making. Nickel-based alloys have a high tolerance to high temperatures and superior anti-corrosion characteristics while maintaining good mechanical properties. Owing to the development of precision casting technology in the late 1950s, a series of highly intensive cast nickel-based superalloys with these properties have been developed. With the rapid changes in the military and civil space industries in recent years, the use of nickel-based superalloys is increasing. In this study, we mainly use Waspaloy as a nickel-based material to study cutting; we use regression analysis to find the significant factors affecting cutting force and surface accuracy and then perform an optimization experiment. A TiAlN-coated tool is mainly used in the study of cutting. We conclude that the significant factors affecting the cutting force among the experimental conditions are the cutting depth and feed rate per tooth and that the significant factors affecting the surface accuracy are the feed rate per tooth and cutting speed. When the cutting depth $d p$ increases from 0.1 to $0.3 \mathrm{~mm}$, the tool wear increases by $94.1 \%$, and when the cutting speed $V_{c}$ increases from 30 to $40 \mathrm{~m} / \mathrm{min}$, the tool wear decreases by $2.17 \%$.

\section{Introduction}

Waspaloy has high tensile strength, fatigue durability, creep strength, and corrosion stability, as well as outstanding weldability and tenacity in high-temperature work environments, so it is often used in environments where high-temperature resistance and load are required. This superalloy is a hard-to-cut material in machining for the following reasons. ${ }^{(1-6)}$

(1) Work hardenability: boundary chipping and edge wear of the cutting clearance increase over time, the cuttings are tough and difficult to break off, and case hardening occurs. ${ }^{(7,8)}$

(2) Low thermal conductivity: although general steel can generate cutting heat when being cut, most of the heat is carried away by the cuttings; however, as Waspaloy has low thermal conductivity, it readily accumulates the cutting heat of the tool and machined part; moreover,

*Corresponding author: e-mail: e6036@ncut.edu.tw

https://doi.org/10.18494/SAM.2020.2596 
it has high yielding point, tensile strength, and cutting resistance, making it easy for the cutting edge to induce high pressure and temperature, and plastic deformation of the tool.

(3) Affinity of the tool and superalloy: in discontinuous cutting, similarly to that observed in milling, the cutting edge and melt, and then the melt are embedded in the workpiece, generating a greater impact force and a cutting edge. ${ }^{(3,4)}$

\section{Material Characteristics}

At present, vacuum induction melting technology is applied to most nickel-based materials. After that, extrusion molding is conducted to obtain Inconel-718 and Waspaloy, and then annealing is performed to homogenize the material with the aim of eliminating the segregation or bands of the crystal structure in the material; the crystal structure of the superalloy is an austenitic high-temperature stable face-centered cubic (fcc) structure. The phases of the crystal structure are shown in Table 1.

Waspaloy is a precipitation-hardening nickel-based superalloy, in which the main precipitation hardening of the $\gamma^{\prime}$ phase differs from that of Inconel-718, and Ti and Al bond to form the $\gamma^{\prime}$ phase. In addition, Waspaloy contains carbon, boron, and zirconium, which are grain boundary strengthening elements. In the $\gamma^{\prime}$ phase, the precipitates of $\mathrm{Ni}_{3} \mathrm{Al}_{\text {or }} \mathrm{Ni}_{3} \mathrm{Ti}$ can strengthen the bonding of elements; the main source of strengthening in Waspaloy is $\gamma^{\prime}$ and the coherent precipitation hardening of the $\gamma^{\prime \prime}$ phase, where $\gamma^{\prime \prime}$ is the main strengthening phase, occurs. ${ }^{(3,4)}$ Parameter control of the hot isostatic pressing process is used to distribute the $\gamma^{\prime \prime}$ phase evenly in large quantities, and the temperature rise in hot isostatic pressing is used to dissolve the $\delta$ phase so as to indirectly increase the number of precipitates in the strengthening phase and improve the mechanical strength of Waspaloy. ${ }^{(9,10)}$

As can be seen from the time-temperature-transformation (TTT) diagram of the nickelbased superalloy in Fig. 1, the precipitation temperature in the $\delta$ phase is higher than that in the $\gamma^{\prime \prime}$ phase. Moreover, according to the long-time temperature variation, the $\delta$ and $\gamma^{\prime}$ phases have smaller contents than the $\gamma^{\prime \prime}$ phase. That is mainly because the $\gamma^{\prime}$ phase can develop the ability to resist creep deformation at high temperatures. The quantities of precipitates in the $\gamma^{\prime}$ phase depend mainly on the chemical components and temperature, as shown in Fig. 2. There are mainly an fcc lattice and randomly distributed solid solute atoms in the $\gamma$ phase, and the original cubic lattice in the $\gamma^{\prime}$ phase, in which nickel atoms accumulate at the center and Al or Ti atoms are distributed in the corners, as shown in Fig. $3 .^{(11-13)}$

Table 1

Phases of Waspaloy.

\begin{tabular}{|c|c|}
\hline & Waspaloy structure \\
\hline Form & Type \\
\hline Primary phase & $\gamma:$ fcc matrix of $\mathrm{Ni}$ \\
\hline Secondary phases & $\begin{array}{l}\gamma^{\prime}: \mathrm{Ni}_{3} \mathrm{Al} \text { or } \mathrm{Ni}_{3} \mathrm{Ti}(\mathrm{fcc}) \\
\gamma^{\prime \prime}: \mathrm{Ni}_{3} \mathrm{Nb} \text { (body-centered tetragonal, bct) } \\
\delta: \mathrm{Ni}_{3} \mathrm{Nb} \text { (orthorhombic) }\end{array}$ \\
\hline Carbides & $\mathrm{MC}, \mathrm{M}_{23} \mathrm{C}_{6}, \mathrm{M}_{6} \mathrm{C}$, and $\mathrm{M}_{7} \mathrm{C}_{3}$ \\
\hline
\end{tabular}




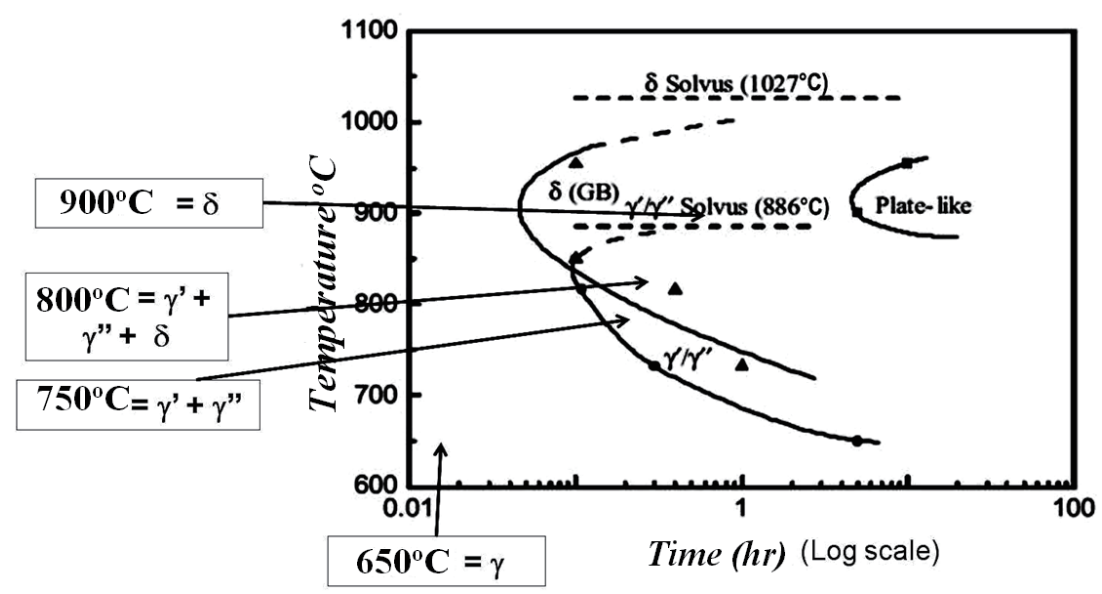

Fig. 1. TTT diagram of the nickel-based superalloy. ${ }^{(11,12)}$

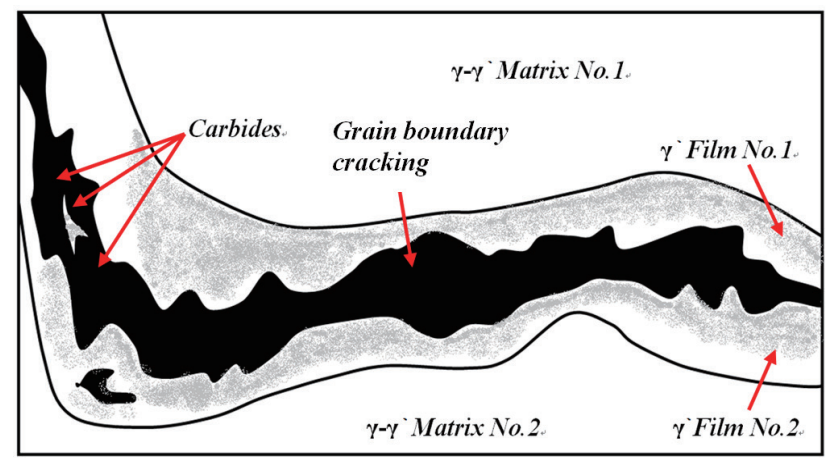

Fig. 2. (Color online) Flow and fracture behavior in the grain boundaries of Waspaloy. ${ }^{(14)}$
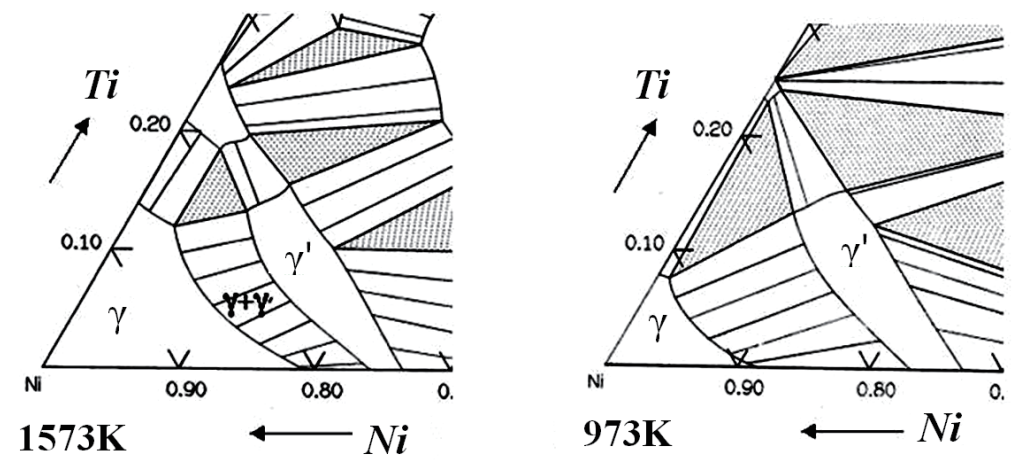

Fig. 3. Ni-Al-Ti ternary phase diagrams showing the $\gamma$ and $\gamma^{\prime}$ phase fields. ${ }^{(11)}$

Waspaloy is a superalloy that has been developed since 1946. The key metallurgical features of the superalloys Inconel-718 and Waspaloy are listed below: (1) solution strengthening elements, such as $\mathrm{W}, \mathrm{Mo}, \mathrm{Co}, \mathrm{Cr}$, and $\mathrm{V}$, produce local lattice strain in the Ni-Fe base to strengthen materials as the radii of these atoms are different from those of the atoms of the base 
material; (2) precipitation hardening elements, such as $\mathrm{Al}, \mathrm{Ti}, \mathrm{Nb}$, and $\mathrm{Ta}$, can form coherent $\mathrm{A}_{3} \mathrm{~B}$ intermetallic compounds, such as $\mathrm{Ni}_{3}(\mathrm{Al}, \mathrm{Ti})$ and other strengthening phases $\left(\gamma^{\prime}\right)$, to strengthen the alloy effectively and obtain high-temperature strength greater than that of ironbased superalloys and cobalt-based alloys; (3) grain boundary strengthening elements, such as B, $\mathrm{Zr}, \mathrm{Mg}$, and rare-earth elements, can increase the high-temperature strength of the alloy. Table 2 shows the components of Waspaloy and Inconel-718, where the former is a standard nickelbased material with typical properties such as precipitation hardening, high material affinity, and low heat transfer coefficient. ${ }^{(11,12)}$

\section{Research Principles and Methods}

\subsection{Cutting principle}

In addition to the computer numerical control (CNC) machine tool, tools, fixture, and jig, the surface finish and processing efficiency of milled parts also depend on the cutting conditions and parameters such as the cutting speed, feed rate, cutting depth, and cutting width. Different cutting conditions produce different results, affecting the available lifetime of the tool as well as the processing quality. ${ }^{(20)}$ The cutting speed, feed rate, cutting depth, and cutting width are usually all set by CNC programming. The cutting speed has the greatest effect on the surface finish and efficiency (Fig. 4).

Table 2

Chemical compositions of Waspaloy and Inconel-718.

\begin{tabular}{llcccccccccc}
\hline & $\mathrm{Cr}$ & $\mathrm{Ni}$ & $\mathrm{Co}$ & $\mathrm{Mo}$ & $\mathrm{W}$ & $\mathrm{Ti}$ & $\mathrm{Al}$ & $\mathrm{Fe}$ & $\mathrm{C}$ & $\mathrm{Nb}$ & Other \\
\hline Inconel-718 & 18 & $\mathrm{~B}$ & 0 & 2.8 & 0 & 1 & 0.5 & 18 & 0.025 & 5.4 & - \\
Waspaloy & 19.4 & $\mathrm{~B}$ & 13 & 4.3 & 0 & 3 & 1.5 & $2 \mathrm{Max}$ & 0.035 & 0 & - \\
\hline
\end{tabular}

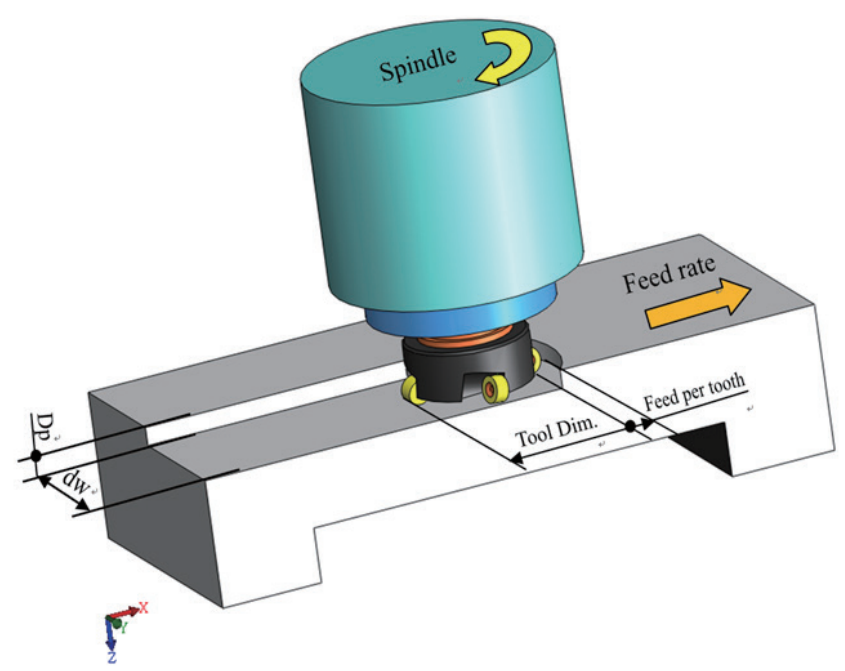

Fig. 4. (Color online) Diagram of cutting parameters. 
The following equation gives the cutting speed $V_{c}$ in terms of the tool diameter $D$ and spindle rotation speed $N$.

$$
V_{c}=\frac{\pi \times D \times N}{1000} .
$$

The feed rate $F$ refers to how fast a milling tool moves through the material being cut. This is calculated using the feed per tooth $F_{z}$ to give the distance in millimeters per minute that a milling bit can move through a particular material as follows:

$$
F=N \times T \times F_{t},
$$

where $N$ is the spindle rotation speed and $T$ is the number of teeth. Ideal surface roughness is a function of only the tool feed per tooth and geometry. It represents the best possible finish that can be obtained for the given tool shape and feed per tooth. It can be shown that the surface roughness of a workpiece is closely related to the feed and corner radius as follows, where $R_{\max }$ is the height of the profile and $R$ is the radius of the rounded corner of the cutting tool (Fig. 5):

which simplifies to

$$
R_{\max }=\frac{F_{t}}{8\left(\frac{R}{F_{z}} \pm \frac{Z}{\pi}\right)} \times 10^{3},
$$

$$
R_{\max }=\frac{F_{t}}{8 r} \times 10^{3} .
$$

\subsection{Exponential smoothing principle}

Exponential smoothing is a particular type of moving average technique applied to time series data, which are used to make forecasts. When the trend of a time series is a linear curve, single exponential smoothing is used for analysis and forecasting, and when the trend is

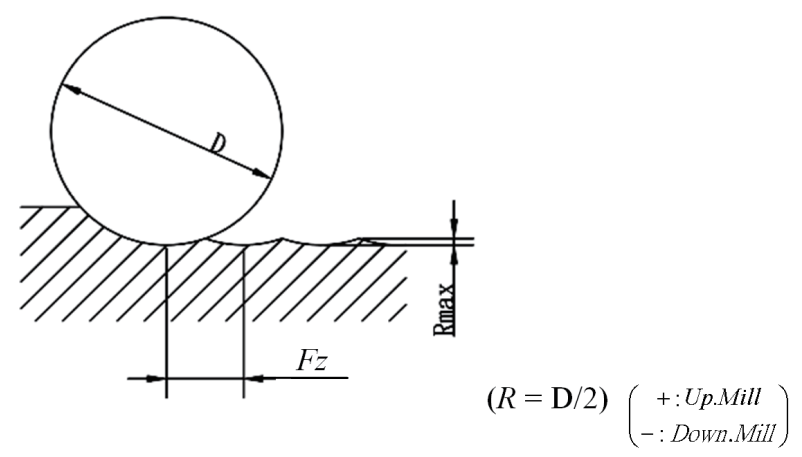

Fig. 5. Main process parameters in milling. 
a quadratic curve, triple exponential smoothing is used. The principle of double exponential smoothing is similar to that of triple exponential smoothing, where the formulas used in the latter are as follows: ${ }^{(17-20)}$

$$
\begin{gathered}
S_{t}^{(1)}=\alpha Y_{t}+(1-\alpha) S_{t-1}^{(1)}, \\
S_{t}^{(2)}=\alpha S_{t}^{(1)}+(1-\alpha) S_{t-1}^{(2)}, \\
S_{t}^{(3)}=\alpha S_{t}^{(2)}+(1-\alpha) S_{t-1}^{(3)} .
\end{gathered}
$$

Trend forecasting by exponential smoothing is mainly performed by calculating the sum of forecast values and the trend correction value. The forecasting model of triple exponential smoothing is

$$
R a_{t+T}=a_{t}+b_{t} T+c_{t} T^{2}
$$

where $a_{t}, b_{t}$, and $c_{t}$ are undetermined coefficients and can be obtained as follows from the fitted curve:

$$
\begin{gathered}
a_{t}=3\left(S_{t}^{(1)}-S_{t}^{(2)}\right)+S_{t}^{(3)}, \\
b_{t}=\frac{\alpha}{2(1-\alpha)^{2}}\left[(6-5 \alpha) S_{t}^{(1)}-2(5-4 \alpha) S_{t}^{(2)}+(4-3 \alpha) S_{t}^{(3)}\right], \\
c_{t}=\frac{\alpha}{2(1-\alpha)^{2}}\left(S_{t}^{(1)}-2 S_{t}^{(2)}+S_{t}^{(3)}\right) .
\end{gathered}
$$

\section{Experimental Equipment and Parameters}

Here, we study a machining center for milling, where the experimental equipment is shown in Table 3. The main cutting parameters are cutting speed, feed rate, and cutting depth, as shown in Table 4. The main purpose of varying the parameters is to optimize the data in the most economical and effective way with the existing equipment, and we then further analyze the optimized data through the use of statistics. The experimental flow is shown in Fig. 6.

\section{Results and Discussion}

In this study, we mainly analyze the relationship between the surface roughness and tool wear of Waspaloy; we find significant factors using regression analysis and perform modeling and optimization experiments. 
Table 3

Experimental equipment.

\begin{tabular}{lc}
\hline Equipment name & Specifications and model \\
Machining center for milling & $\begin{array}{r}X / Y / Z \text {-axis stroke: } 1020 / 520 / 505 \mathrm{~mm} \\
\text { Maximum speed of spindle: } 10000 \mathrm{rpm}\end{array}$ \\
$\begin{array}{l}\text { Milling tool blade } \\
\text { (RCKT1204M-MM2040) }\end{array}$ & $\begin{array}{c}\text { Blade diameter: } 12 \mathrm{~mm} \\
\text { Blade angle } R: 6 \mathrm{~mm}\end{array}$ \\
$\begin{array}{l}\text { Milling tool shank } \\
\text { (R200-024A32-16M) }\end{array}$ & $\begin{array}{c}\text { Nool diameter: } 40 \mathrm{~mm} \\
\text { Number of blades: } 3\end{array}$ \\
$\begin{array}{l}\text { Surface roughness gauge } \\
\text { Model: MarSurf PS1 }\end{array}$ & $\begin{array}{l}\text { Range: } 0.25 \text { to } 2.5 \\
\text { Recorded value: } \mathrm{Ra}\end{array}$ \\
\hline
\end{tabular}

Table 4

Experimental parameters and levels.

\begin{tabular}{lcc}
\hline Parameters & Low level & High level \\
\hline Cutting depth $(\mathrm{mm})$ & 0.1 & 0.3 \\
Cutting width $(\mathrm{mm})$ & 40 & 40 \\
Cutting speed $(\mathrm{m} / \mathrm{min})$ & 30 & 40 \\
Feed per tooth $(\mathrm{mm} /$ tooth $)$ & 0.1 & 0.3 \\
\hline
\end{tabular}

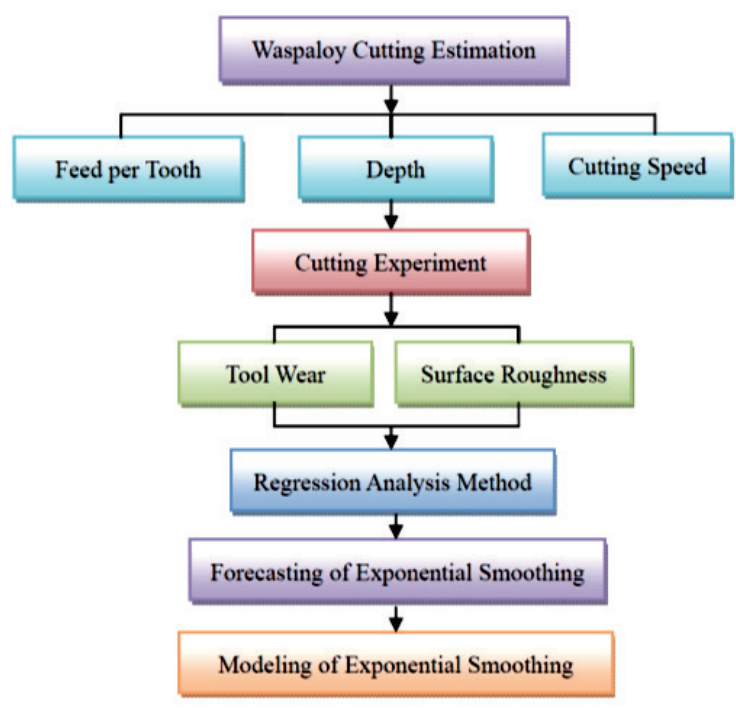

Fig. 6. (Color online) Experimental flow graph.

\subsection{Screening experiment}

The methods that can be used to select significant factors are a full factorial experiment and a fractional factorial experiment. The former is used in this study for the test and analysis. 
We use the experimental form designed by a parametric programming matrix to obtain data from cutting experiments for analysis, where the variable factors are cutting depth, cutting speed, and feed per tooth and the objective function is the surface accuracy. Figure 7 shows the tool wear. The flank wear and rake face wear of the tool are observed at the same time; an increase in flank wear will increase the tool wear area and vice versa. The feed per tooth and cutting depth are proportional to the tool wear, and the cutting speed is inversely proportional to the tool wear. When the feed per tooth $F_{t}$ increases from 0.1 to $0.3 \mathrm{~mm} /$ tooth, the tool wear increases by $17.8 \%$, when the cutting depth $d p$ increases from 0.1 to $0.3 \mathrm{~mm}$, the tool wear increases by $94.1 \%$, and when the cutting speed $V_{c}$ increases from 30 to $40 \mathrm{~m} / \mathrm{min}$, the tool wear decreases by $2.17 \% .^{(15,16)}$

The analysis of variance is used for the data analysis; furthermore, the test coefficient $R^{2}$ is found to be $75 \%$ and the analysis of variance is used to analyze $V_{c}, F$, and $d p$. Surface roughness was significantly contributed by the feed per tooth in the model $\left(R^{2}=76.6 \%\right)$; thus, the applicability of the test coefficient can be determined by $R^{2}$. We do not consider interactions between three or more variables, and we examine the normal plot of the standardized effects and the Pareto chart of the standardized effects as shown in Fig. 8. There is a vertical broken line passing through 0.703 on the $X$-axis in Fig. $8(b)$, representing $\alpha(P$ value $)=0.5$. According to the residual analysis graphs, the feed rate has the largest effect on the surface roughness and the cutting depth has the smallest effect.

We write the principal factors $\mathrm{A}, \mathrm{B}$, and $\mathrm{C}$, and the interactions between them $\mathrm{AB}, \mathrm{BC}$, and $\mathrm{AC}$ in an ANOVA table. The significant factors or interactions with $P<0.5$ are $\mathrm{B}$ (feed per tooth), $\mathrm{C}$ (cutting speed), and $\mathrm{AB}$ (cutting depth and feed per tooth). From the main effect plot for $\mathrm{Ra}$ and the interaction plot for Ra in Fig. 8, the factor with the greatest effect on the surface accuracy is found to be the feed per tooth, followed by the cutting speed. Regarding
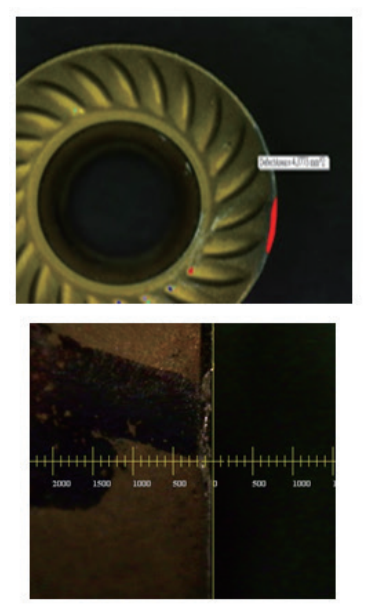

(a)
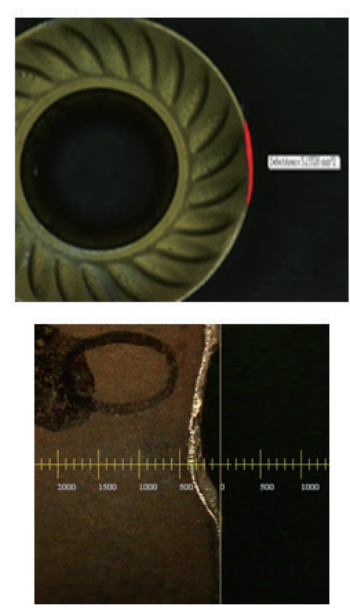

(b)
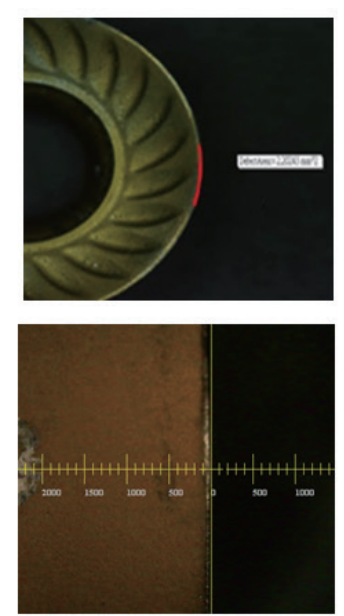

(c)
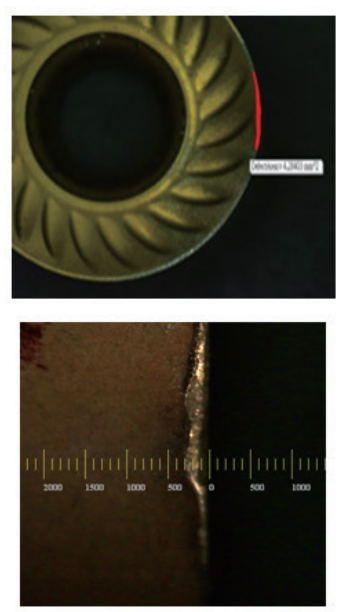

(d)

Fig. 7. (Color online) Diagrams of tool wear in experiment. (a) $F_{t}=0.1 \mathrm{~mm} / \mathrm{tooth}, d p=0.3 \mathrm{~mm}$, and $V_{c}=30 \mathrm{~m} / \mathrm{min}$, (b) $F_{t}=0.3 \mathrm{~mm} /$ tooth, $d p=0.3 \mathrm{~mm}$, and $V_{c}=30 \mathrm{~m} / \mathrm{min}$, (c) $F_{t}=0.1 \mathrm{~mm} /$ tooth, $d p=0.1 \mathrm{~mm}$, and $V_{c}=40 \mathrm{~m} / \mathrm{min}$, and (d) $F_{t}=0.1 \mathrm{~mm} /$ tooth,$d p=0.3 \mathrm{~mm}$, and $V_{c}=40 \mathrm{~m} / \mathrm{min}$. 


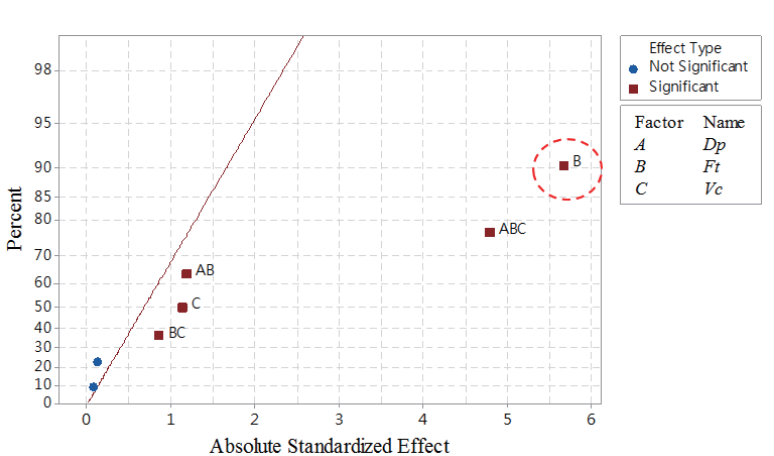

(a)

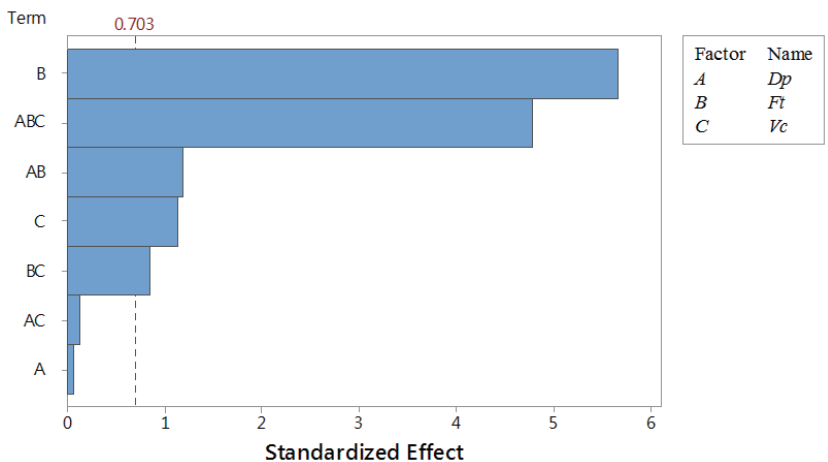

(b)

Fig. 8. (Color online) Residual analysis graphs: (a) Half normal plot of the standardized effects (response is Ra, $\alpha=0.50$ ) and (b) Pareto chart of the standardized effects (response is $\mathrm{Ra}, \alpha=0.50$ ).

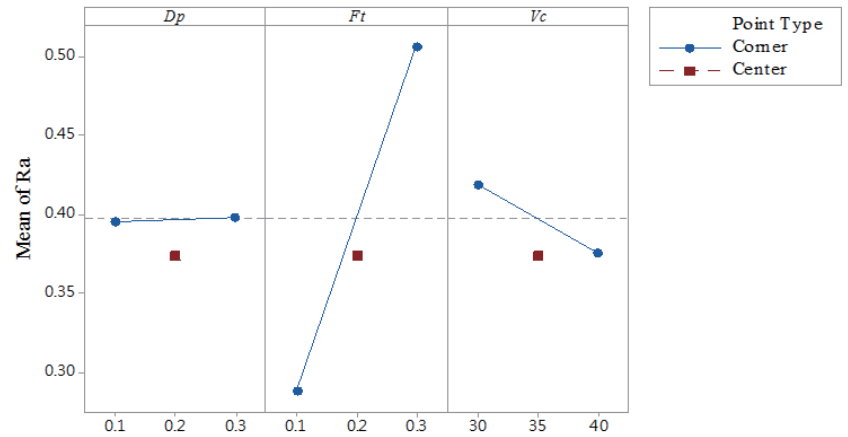

(a)

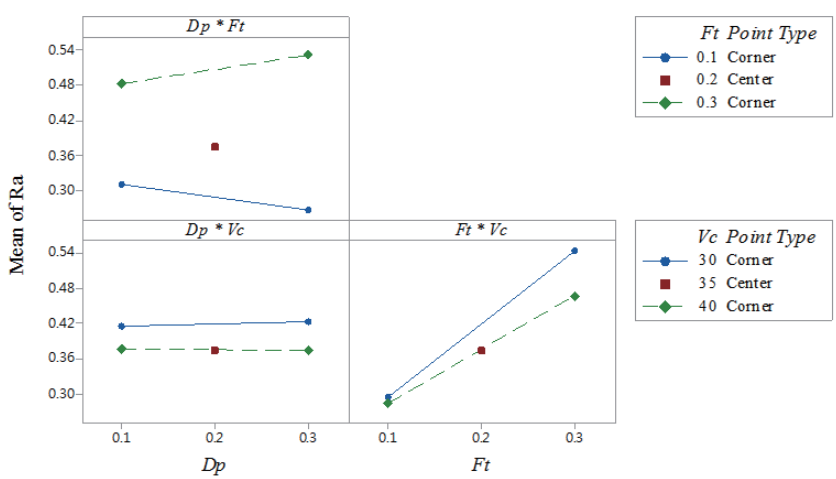

(b)

Fig. 9. (Color online) Effect analysis graphs. (a) Main effect plot for Ra and (b) interaction plot for Ra.

the interaction between factors, as the cutting depth is not a significant factor, the factors interacting with the cutting depth are not considered (Fig. 9), and the feed per tooth and surface accuracy are discussed.

\subsection{Surface accuracy prediction}

The exponential smoothing method (ESM) is used to estimate the difference between the surface roughness of Waspaloy when being cut and the actual measurement; the ESMs mainly include the first exponential smoothing to the third exponential smoothing. When the cutting speed $V$ is $40 \mathrm{~mm} / \mathrm{min}$ and the cutting depth $d p$ is $0.3 \mathrm{~mm}$, we observe that if the smoothing constant is $\alpha=0.5$, then the accuracy is not varying. The result of the analysis is shown in Fig. 10. When the feed rate increases, the surface accuracy also increases. This is mainly because the feed rate is an important factor that affects the surface accuracy, which can be found from Eq. (4); the ESM prediction curve has the same trend as the experimental values, but the errors are large when the smoothing constant is increased to $\alpha=0.8$ (Fig. 11). Nevertheless, the ESM prediction 


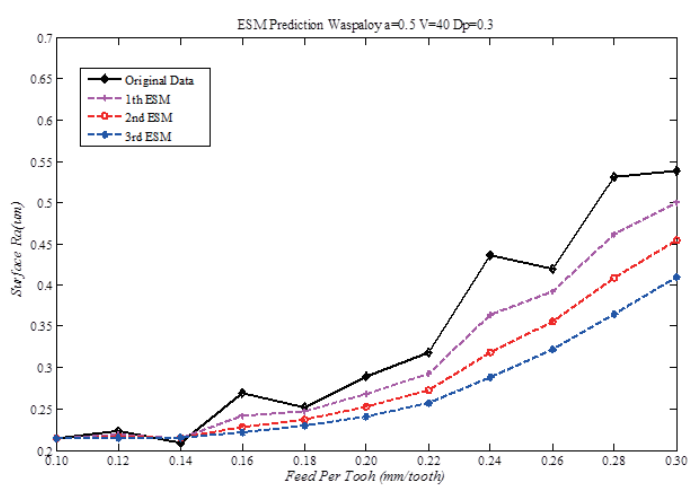

Fig. 10. (Color online) Analysis chart of feed rate and surface accuracy $(V=40 \mathrm{~m} / \mathrm{min}, \alpha=0.5)$.

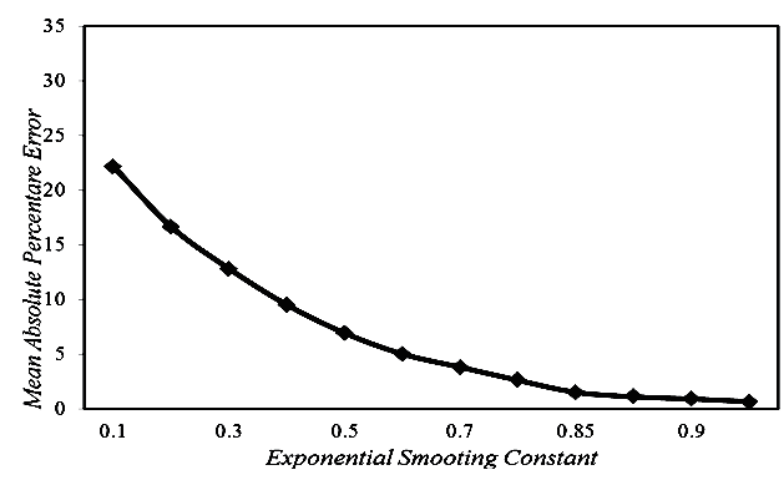

Fig. 12. Variation of MAPE for different $\alpha$ values.

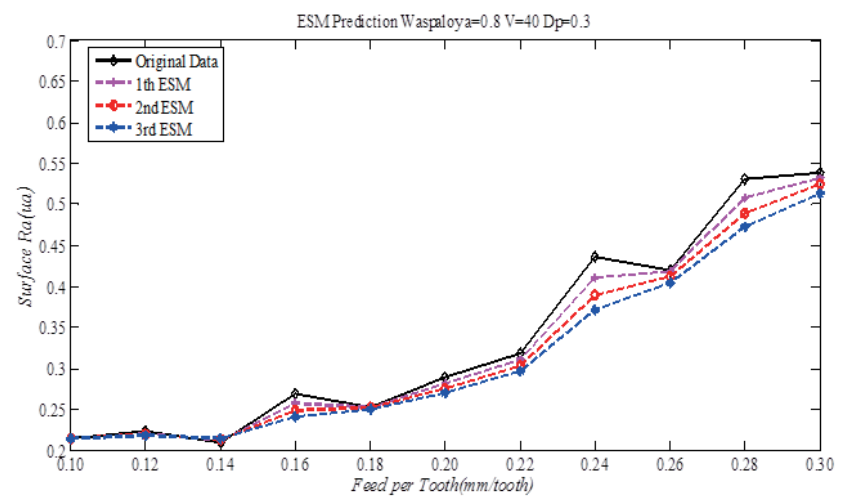

Fig. 11. (Color online) Analysis chart of feed rate and surface accuracy $(V=40 \mathrm{~m} / \mathrm{min}, \alpha=0.8)$.

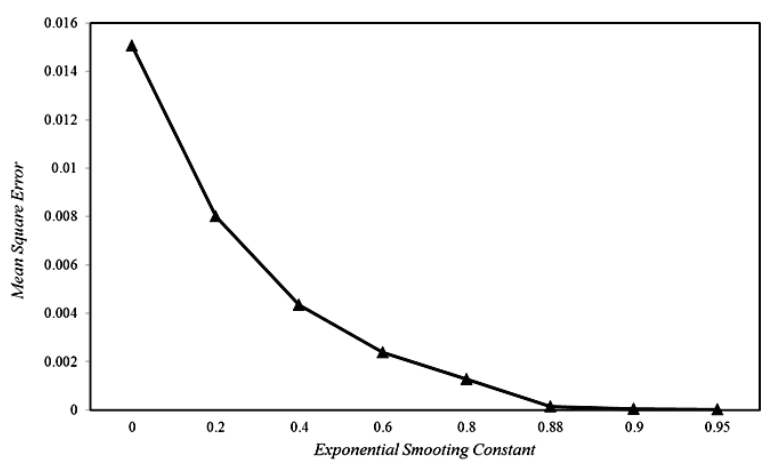

Fig. 13. Variation of MSE for different $\alpha$ values.

curve has a similar trend to the experiment values. The errors of the single ESM curve are smaller than those of the triple ESM curve, mainly because errors compound each other in the latter, resulting in larger errors.

\subsection{Modeling of exponential smoothing}

As the material characteristics of Waspaloy cause severe wear of the tool, the surface accuracy decreases, so it is important to predict the tool life and surface accuracy. The regression analysis showed that the feed rate is a significant factor. When establishing the exponential smoothing model, we first observe the mean absolute percentage error (MAPE), which is used as an indicator to evaluate the accuracy of the prediction model; when MAPE is less than $10 \%$, the prediction is highly accurate. Figure 12 shows that when the smoothing constant $\alpha$ is greater than 0.4 , MAPE is less than $10 \%$, indicating highly accurate prediction. ${ }^{(20)}$

Different exponential smoothing constants have different mean square errors (MSEs) and mean absolute errors (MAEs), as shown in Table 5. If MSE and MAE are smaller, the accuracy is higher (Fig. 13). When $\alpha \geq 0.88$, the curve converges, so $\alpha$ should be 0.88 when exponential smoothing is used for modeling. Because the low thermal conductivity and thermosetting of 
Table 5

MSE/MAE/MAPE values of different smoothing constants.

\begin{tabular}{llllllllllllc}
\hline & 0.1 & 0.2 & 0.3 & 0.4 & 0.5 & 0.6 & 0.7 & 0.8 & 0.85 & 0.88 & 0.9 & 0.95 \\
\hline MSE & 0.0150 & 0.0080 & 0.0043 & 0.0024 & 0.0013 & 0.0007 & 0.0003 & 0.0001 & $7.03 \mathrm{E}-05$ & $4.41 \mathrm{E}-05$ & $3.05 \mathrm{E}-05$ & $7.52 \mathrm{E}-06$ \\
MAE & 0.0909 & 0.0674 & 0.0500 & 0.0369 & 0.0269 & 0.0190 & 0.0128 & 0.0079 & 0.0057 & 0.0045 & 0.0038 & 0.0019 \\
MAPE & 21.86 & 16.46 & 12.39 & 9.27 & 6.83 & 4.89 & 3.31 & 2.09 & 1.53 & 1.22 & 1.02 & 0.52 \\
\hline
\end{tabular}

Table 6

Prediction models of exponential smoothing.

\begin{tabular}{llll}
\hline Feed rate & \multicolumn{1}{c}{ Prediction equation } & Feed rate & Prediction equation \\
\hline$F_{t}=0.12 \mathrm{~mm} /$ tooth & $R a_{0.12}=0.223+0.018 T+0.0031 T^{2}$ & $F_{t}=0.22 \mathrm{~mm} /$ tooth & $R a_{0.22}=0.318+0.032 T+0.002 T^{2}$ \\
$F_{t}=0.14 \mathrm{~mm} /$ tooth & $R a_{0.14}=0.209-0.0196 T-0.0067 T^{2}$ & $F_{t}=0.24 \mathrm{~mm} /$ tooth & $R a_{0.24}=0.436+0.145 T+0.031 T^{2}$ \\
$F_{t}=0.16 \mathrm{~mm} /$ tooth & $R a_{0.16}=0.269+0.079 T+0.023 T^{2}$ & $F_{t}=0.26 \mathrm{~mm} /$ tooth & $R a_{0.26}=0.420-0.043 T-0.035 T^{2}$ \\
$F_{t}=0.18 \mathrm{~mm} /$ tooth & $R a_{0.18}=0.252-0.030 T-0.0178 T^{2}$ & $F_{t}=0.28 \mathrm{~mm} /$ tooth & $R a_{0.28}=0.531+0.133 T+0.030 T^{2}$ \\
$F_{t}=0.20 \mathrm{~mm} /$ tooth & $R a_{0.20}=0.289+0.044 T+0.011 T^{2}$ & $F_{t}=0.30 \mathrm{~mm} /$ tooth & $R a_{0.30}=0.539-0.009 T-0.023 T^{2}$ \\
\hline
\end{tabular}

1. Tool form: R200-024A32-16M.

2. Machining parameters: cutting speed $V_{c}=40 \mathrm{~mm} / \mathrm{min}$; cutting depth $d p=0.3 \mathrm{~mm}$.

Waspaloy make it difficult to process, and it can be seen from the thermal diffusivity formula that the thermal conductivity is proportional to the thermal diffusion, the exponential smoothing model should be divided into the heating and thermal diffusion stages. Here, we mainly predict the temperature changes at the location with the maximum temperature; equations predicting the temperature during the machining process and the prediction models are provided in Table 6. These temperature changes are predicted mainly from the instantaneous heating time.

\section{Conclusions}

In the machining of nickel-based materials, the main factor that affects the surface accuracy is the feed rate, which can be obtained from the regression analysis method, while the cutting speed and depth have very small effects on the surface accuracy. In addition, a very high cutting temperature causes precipitation hardening, and the affinity between the material and the tool causes rapid cracking of the tool.

A tool is rapidly worn when cutting Waspaloy. The feed per tooth and cutting depth are proportional to the tool wear; when the cutting depth $d p$ was increased from 0.1 to $0.3 \mathrm{~mm}$, the tool wear increased by $94.1 \%$, and when the cutting speed $V_{c}$ was increased from 30 to $40 \mathrm{~m} / \mathrm{min}$, the tool wear decreased by $2.17 \%$.

When an exponential smoothing model was used for prediction, the errors of the single exponential smoothing curve were found to be smaller than those of the triple exponential smoothing curve, mainly because errors were compounded in the triple exponential smoothing curve.

When exponential smoothing is used for modeling, the smoothing constants can affect the model accuracy, so MAPE was used to observe the accuracy. When the smoothing constant $\alpha$ was greater than 0.4 , MAPE was less than $10 \%$, indicating highly accurate prediction. The smoothing constant $\alpha$ should be 0.88 when exponential smoothing is used for modeling because MSE approaches the convergence value. 


\section{Nomenclature}

$V_{c}=$ Cutting speed $(\mathrm{m} / \mathrm{min})$

$N=$ Spindle speed (rev/min)

$D=$ Tool diameter $(\mathrm{mm})$

$F=$ Feed rate $(\mathrm{mm} / \mathrm{min})$

$Z=$ Insert number

$d p=$ Cutting depth $(\mathrm{mm})$

$F_{t}=$ Feed per tooth (mm/tooth)

$S_{t}=$ Exponential smoothing value at time $t$.

$Y_{t}=$ Actual value at time $t$.

$S_{t-1}=$ Exponential smoothing value at time $t-1$.

$\alpha=$ Smoothing constant in $[0,1]$.

$S_{t}^{(3)}=$ Cubic exponential smoothing value at time $t$.

\section{References}

1 M. T. Tan: Annals of the CIRP 35 (1986) 71. https://doi.org/10.1016/S0007-8506(07)61841-1

2 H. H. Habeeb, K. A. Abou-R1-Hossein, and B. Mohamad: Asian J. Sci. Res. 1 (2008) 222. https://doi. org/10.3923/ajsr.2008.222.230

3 S. M. Bahatia, P. C. Pandey, and H. S. Shaw: Wear 51 (1978) 201. https://doi.org/10.1016/0043-1648(78)902600

4 E. O. Ezugwu, Z. M. Wang, and A. R. Machado: J. Mat. Proc. Tec. (1998) 1. https://doi.org/10.1016/S09240136(98)00314-8

5 D. Dudzinski, A. Devillez, A. Moufki, D. Larrouquere, V. Zerrouki, and J. Vigneau: Int. J. Mach. Tools Manuf. 44 (2004) 439. https://doi.org/10.1016/S0890-6955(03)00159-7

6 J. Deepu, P. Kuppan, A. S. SBalan, and R. Oyyaravelu: Mat. Sci. Eng. 149 (2016) 012012. https://iopscience. iop.org/article/10.1088/1757-899X/149/1/012012/pdf

7 H. T. Ding and Y. C. Shin: Int. J. Adv. Manuf. Tech. 64 (2013) 475. https://doi.org/10.1007/s00170-012-4012-8

8 S. C. Wang: Exponential Smoothing for Forecasting and Bayesian Validation of Computer Models, Ph.D. Dissertation, Industrial and Systems Engineering Georgia Institute of Technology (2006).

9 C. H. Che Haron, A. Ginting, and J. H. Goh: J. Mat. Proc. Tec. 116 (2001) 49. https://doi.org/10.1016/s09240136(01)00841-X

10 S. H. I. Jaffery and P. T. Mativenga: Int. J. Adv. Manuf. Tech. 58 (2012) 479. https://doi.org/10.1007/s00170-011$3427-y$

11 A. Li, R. Roberts, P. Haldipur, F. J. Margetan, and R. B. Thompson: AIP Conf. Proc. 657 (2003) 117.

12 P. Haldipur, F. J. Margetan, and R. B. Thompson: Rev. Quant. Nondestr. Eval. 22 (2003) 1335. https://doi. org/10.1063/1.1570289

13 D. H. Zhu, X. M. Zhang, and H. Ding: Int. J. Mach. Tools Manuf. 64 (2013) 60. https://doi.org/10.1016/ j.ijmachtools.2012.08.001

14 C. T. Sims and W. C. Hagel: The Superalloys (John Wiley, New York, 1972).

15 P. Haldipur and R. B. Thompson: Material Characterization of Nickel-based Superalloys Through Ultrasonic Inspection, Ph.D. Dissertation, Iowa State University (2006).

16 F. E. Stanke and G. S. Kino: J. Acoust. Soc. Am. 75 (1984) 665. https://doi.org/10.1121/1.390577

17 R. J. Hyndman, A. B. Koehler, R. D. Snyder, and S. Grose: Int. J. Fore. 18 (2002) 439. https://doi.org/10.1016/ S0169-2070(01)00110-8

18 S. K. Paul: Global J. Res. Eng. 11 (2011) 31. http://globaljournals.org/GJRE_Volume11/7-Determination-ofExponential-Smoothing-Constant-to.pdf

19 E. S. Gardner: Int. J. Fore. 22 (2006) 637. https://doi.org/10.1016/j.ijforecast.2006.03.005

20 E. McKenzi and E. S. Gardner: Int. J. Fore. 26 (2010) 661. https://doi.org/10.1016/j.ijforecast.2009.07.001 


\section{About the Authors}

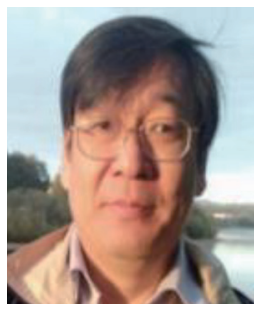

Shao-Hsien Chen received his B.S. degree from National Chin-Yi University of Technology, Taiwan, in 1992, and his M.S. and Ph.D. degrees from National Chung Cheng University, Taiwan, in 2001 and 2006, respectively. From 2005 to 2009, he was an R\&D manager at Ching Hung Machinery \& Electric Industrial Co., Ltd. and AWEA Machinery \& Electric Industrial Co., Ltd. Taiwan. Since 2009, he has been an assistant professor at National Chin-Yi University of Technology. His research focuses on smart machines, machine tool design, and superalloy machining. (e6036@ncut.edu.tw)

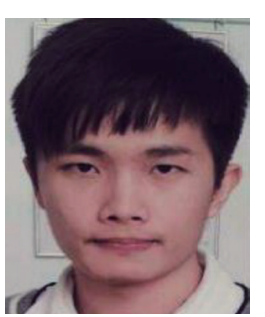

Yu-Lun Ho received his B.S. degree from National Chin-Yi University of Technology, Taiwan, in 2013, and his M.S. degree from National ChinYi University of Technology, Taiwan, in 2015. Since 2015, he has been an engineer at Litz Machine Tool Corp., Taiwan. His research focuses on smart machines and machine tool design. 